\title{
ACTUAL PROBLEMS OF TEACHING SOCIAL AND HUMANITARIAN DISCIPLINES IN THE CONDITIONS OF TRANSFORMATION OF MODERN TECHNICAL EDUCATION
}

\author{
Svetlana Korshunova ${ }^{1 \star}$, Nadezhda Lapynina ${ }^{2}$, Maria Marina ${ }^{3}$ \\ ${ }^{1}$ Candidate of philosophical Sciences, Associate Professor, Voronezh State Technical University, \\ Russia, E-mail: skorsh5@gmail.com \\ ${ }^{2}$ Candidate of philological Sciences, Associate Professor, Voronezh State Technical University, \\ Russia, E-mail: nn.lapynina@mail.ru \\ ${ }^{3}$ Director of the Museum of engineering, Voronezh State Technical University, Russia, E-mail: \\ mary.medvedeva84@yandex.ru \\ ${ }^{*}$ Corresponding Author
}

\begin{abstract}
The article considers the features of transformation of technical education in the conditions of formation of a digital society. The authors reveal the role of human capital in the modern economy, which is carried by University graduates. The use of the predictive method helped to analyze the requirements that the digital economy will soon impose on students of technical universities. The main competencies necessary for a modern professional are highlighted, which include not only theoretical and applied engineering knowledge, but also an aggregate of new professional and socio-cultural competencies.

The authors consider in detail the internal content of soft skills, which they understand as a key intangible asset in the structure of human capital. It is proved that only social and humanitarian disciplines are fully capable of providing the formation of these soft skills.

The authors conclude that it is necessary to strengthen the role of social and humanitarian knowledge in technical education, since it meets the needs of the digital society and can ensure the unity of intuitive, emotional, visual, and logical thinking of a modern specialist.
\end{abstract}

Keywords: Digital society, digitalization, human capital, soft skills, competence, professional competence, technical universities, social and humanitarian knowledge.

\section{INTRODUCTION}

Currently, the social institution of education is in the process of deep transformation. Education, as well as the entire society, is experiencing the consequences of the fourth industrial revolution, associated with the development of information (digital) technologies. Digital technologies, on the one hand, provide new opportunities, including in the educational sphere, on the other hand, they radically change the way of life of modern people, form a new type of economic relations-the digital economy. The rapid growth of digitalization of the world economy has strengthened the global trend associated with the increasing role of human capital 
as the main driver of economic development (Kuzminov, Frumin, 2018, p. 11). In the XXI century, the quality of human capital is formed primarily by the Institute of education. "In the context of the formation of a digital society, the main subject of technological changes is gradually becoming the youth as a social group, which has previously adopted new forms of social communication" (Korshunova, 2020, p.110).

Consequently, young professionals and University graduates become carriers of modern human capital. For this reason, their knowledge, skills, abilities and motivations must meet the requirements that the new digital society imposes on the internal content of human capital. It is obvious that in such conditions, the education system must meet the demands of the modern digital economy, which acts as its main customer (VaindorfSysoeva, Subocheva, 2018, pp. 25-36).

Russia has already started implementing the Federal project "Personnel for the digital economy", and activities were held that brought together the best experts of the global education system to find new ways to develop higher education. The evaluation of the effectiveness of Russian higher education shows that it is largely behind the dynamic processes that occur in the modern economy and society as a whole. For example, the study "Russia 2025: from personnel to talent", conducted jointly by BCG, WorldSkills Russia and Global Education Futures with the support of Sberbank in 2017, indicates certain problems in providing the country with human resources ("Russia 2025: resetting the talent balance", 2017).

This gap is especially noticeable in technical education, although it is intended to focus on the production sector. This means that graduates of technical universities do not have the necessary qualities in the new economic conditions. Therefore the University community currently faces an actual task - not just to modernize technical education, but to develop a new educational paradigm that will contribute to the formation of future specialists with special professional competencies that are in demand in the digital economy [15]. Performing this task, it is necessary, in our opinion, to review the complex of academic disciplines included in the educational programs, to analyze the place and role of social and humanitarian disciplines in the curricula of technical universities, as well as to develop new methodological approaches to teaching these disciplines (Korshunova, 2018, pp. 92-94).

The purpose of this research is to analyze the requirements that the Digital economy imposes on modern graduates of technical universities, to identify the main set of competencies that a modern specialist should possess, and to consider the role of social and humanitarian disciplines in the formation of the necessary knowledge, skills and abilities for a graduate of a technical University.

\section{METHODOLOGY}

When considering the global processes of formation of the digital economy, which imposes new professional requirements on graduates of technical universities, a certain scientific methodology was used, which included the following research methods: system, value-oriented, predictive, synergetic methods, as well as the method of functional analysis.

The systematic method allowed us to identify education as one of the social institutions of society and to comprehend the process of transformation of the modern education system as a consequence of the digitalization of post-industrial society. Using the predictive method, it was possible to analyze new requests for professional specialists that are formed in the depths of the digital economy. The value-oriented method allowed us to identify new value orientations and motivations that determine the specifics of human capital, which is carried by modern University graduates. The use of synergetic methodology allowed us to understand the complex situation of uncertainty in which the modern education system is located. Finally, the method of functional analysis allowed us to identify the functional capabilities of social and humanitarian disciplines, which, having a huge range of forms and methods of cognitive activity can be the basis for the formation of key competencies of future specialists.

\section{DISCUSSION}

A characteristic feature of our time is the change in value orientations, the formation of new standards and activities, and therefore the emergence of new requirements for specialists of different professions. The modern approach to professional education reject the traditional task of promoting the assimilation of a certain amount of knowledge obtained in the course of studying the necessary technical disciplines (Tchoshanov, 2018, pp. 53-62). The digital society imposes requirements on graduates of technical universities, which include not only a high level of theoretical and applied engineering knowledge, but also a number of new professional and socio-cultural competencies.

Competence is a specific task that a specialist must effectively solve in a particular field of activity, based on 
the necessary knowledge, skills and abilities. Competencies are necessary for the implementation of the main types of professional activities of a specialist.

Professional competencies include: availability of knowledge, skills, abilities necessary for work in the specialty; autonomy and flexibility in solving professional problems; ability to work with information, make responsible decisions; a combination of knowledge, abilities and attitudes that allows you to successfully carry out activities in the modern working environment; a conscious positive attitude to your profession, striving for continuous improvement and growth.

Thus, the specialist must have the necessary set of competencies, which in turn will characterize him as a competent professional.

A modern graduate of a technical University is not always prepared for independent professional activity in the new economic conditions, even if he has a sufficiently high level of fundamental and applied knowledge. Conditions in the labor market are changing rapidly, in addition, the formation of an innovative technological paradigm based on the digital economy creates a situation of complete uncertainty for a University graduate. The usual approach to choosing a future profession no longer works, since experts predict the disappearance of many traditional professions and the emergence of new specialties ("Atlas of new professions").

As a result, a young specialist should be prepared to change the nature and even the scope of their work, to the fact that the content and meaning of their work responsibilities may change repeatedly, and the list of additional knowledge and skills will steadily grow throughout their professional career.

The most important manifestation of a specialist's professionalism is the ability to free creative activity, to the practical reconstruction of the world. This ability is largely due to the formation and development of intellectual professional culture of the individual. It manifests itself in professional growth, in the desire to acquire new knowledge, and in the ability to solve complex professional tasks in a dynamically developing economy.

At the same time, the competence of a modern specialist should include not only professional competencies, but also the so-called Soft skills. According to most researchers, these skills are an important intangible asset for modern carriers of human capital (Matteson, Anderson and Boyden, 2016, pp. 71-88).

Although there is no officially agreed, universal set of soft skills, they include communication skills, selfdevelopment, teamwork skills, problem solving skills and critical thinking, creative thinking, empathy, emotional intelligence, and leadership skills (Mitchell, Pritchett, and Skinner, 2013, p. 89). In addition, soft skills include such socially significant qualities as responsibility, self-reflection, and tolerance.

As is known, in the traditional educational paradigm, the cycle of social and humanitarian disciplines was responsible for the formation of students ' social and personal qualities. However, at present, the social and humanitarian Sciences are in a state of deep restructuring. On the one hand, the role of the humanitarian paradigm in the achievements of modern civilization is obvious. Steve Jobs said: "It's technology married with liberal arts, married with the humanities, that yields us the result that makes our hearts sing" (Carmody, 2011). On the other hand, representatives of the Humanities retain their internal passivity and do not show much interest in the practical results of their research (Epshtein, 2016, p. 6). Now we need to rethink the role of the liberal arts in the system of scientific knowledge, and understand what importance social and humanitarian Sciences should have in the formation of the worldview of modern man.

\section{RESULTS}

Cognitive activity in the modern world implies a change in the methodology of teaching social and humanitarian disciplines, as well as the formation of a new style of thinking for students. It is necessary to use the full potential of humanitarian knowledge, which allows us to maintain the unity of intuitive, emotionalsensory, visual-imaginative and logical thinking. Currently, the main role should belong to universities (Kuzminov, 2018, pp. 5-8). However, a modern University often looks like a conveyor that produces numerous specialists with standard skills and abilities. As for technical universities, they have a rather contradictory status. This is a contradiction between the concept of a University, which is an integral system of creating, reproducing and transmitting scientific knowledge, and the applied tasks that are assigned to any technical University today.

Maintaining the traditional approach to education is dangerous because it can turn people into repositories of useless knowledge. The excess of information provided in the program, when the number of hours is reduced, and the amount of material that needs to be conveyed increases, forms a negative perception to 
the learning process. This is especially true for teaching social and humanitarian subjects at a technical University (Raitskaya, Tikhonova, 2018, pp.350-363).

Indifferent or even negative perception of social and humanitarian disciplines by students of a technical University may indicate a lack of motivation to study these Sciences. Often at the University, representatives of the administration and teachers of technical Sciences allow themselves to express the opinion that the Humanities are optional and secondary disciplines. In addition, there are common weaknesses and disadvantages of the entire modern learning process: depersonalization and standardization of the educational process, the informative nature of learning, which does not imply that the student has the ability to think and self-reflection. Having a deep worldview potential, social and humanitarian Sciences should not be just an addition to engineering education. Humanitarian knowledge should become the core of the scientific outlook of the future specialist, contribute to the formation of his beliefs and value orientations. Such disciplines as philosophy, sociology, political science, cultural studies, and psychology will help to form a student's constant desire for reflection, self-reflection, self-knowledge and self-development.

Extensive use of modern information technologies in professional practice requires a specialist to have a developed analytical thinking. The skills of philosophical methodology will help master such cognitive operations as the ability to logical formalization, the ability to concretize the idea of an object, the selection of the internal structure of the object and the relationships in which the object under study consists.

The activity of a modern engineer is connected not only with the technological sphere and the natural environment, but also with the social processes that determine the specifics of modern dynamic development. Therefore, the narrow technical, functional orientation only to natural science, mathematics and technical Sciences, which has long been considered the norm for the training process of technical students, has long been outdated.

We believe that a set of soft skills can be formed, first of all, due to the disciplines of the social and humanitarian cycle. The method of teaching these disciplines involves creating an atmosphere of dialogue and discussion, in which students are able to freely express their positions, forming the ability to communicate, show empathy, and tolerate other opinions.

Social and humanitarian Sciences, generalizing the cultural and historical experience of mankind, make it possible to introduce young people to human socio-cultural values. In this sense, these Sciences perform their axiological function, showing their humanistic potential, which, unfortunately, is absent from the technical Sciences.

\section{CONCLUSION}

Therefore the analysis of the current stage of technical education development demonstrates the leading role of social and humanitarian disciplines, the importance of which was updated in connection with the requirements that modern Economics imposes on a University graduate. Soft skills have become the most important skills for a modern professional, and only social and humanitarian disciplines can fully provide their formation.

To achieve this goal, the modern education system is undergoing a global transformation associated with the transition to a competency-based learning model. The formation of professional competence among University graduates should be carried out by developing a General competence model and creating individual competence profiles.

The General competence model is a set of key competencies that are necessary for effective training and work in the new economic reality. The General competency model includes cognitive, social-emotional, and digital competencies. These competencies are formed, among other things, through the development of soft skills, in the formation of which social and humanitarian disciplines participate. The philosophical Sciences are able to develop such cognitive competencies as critical thinking, problem solving skills, innovative thinking, intellectual load management skills, skills of learning, information skills, and time management skills. Such disciplines as sociology and cultural studies contribute to the development of social and communicative skills (interpersonal skills, teamwork and leadership, social intellect, responsibility, ethics of communication). And psychological and pedagogical disciplines help to form personal attributes and emotional intellect necessary for successful professional activity (integrity, optimism and positive thinking, flexibility, creativity, motivation, empathy) (Raitskaya, Tikhonova, 2019, pp. 4-8).

At the same time, the modern higher education system should provide students with personalized learning opportunities. To do this, in addition to the basic competence model, you should create individual competence profiles that will provide personal development paths for the future specialist. This will allow 
technical universities to expand the curriculum of educational programs and include a sufficient amount of social and humanitarian Sciences, which will eventually lead to an improvement in the quality of human capital, so necessary for modern society.

\section{REFERENCE LIST}

Atlas of new professions: http://atlas100.ru/index/, last accessed 2020/03/16.

Epshtein M., (2016). From knowledge to creativity: how Humanities can change world. Moscow; Saint Petersburg: Center for Humanitarian Initiatives.

Carmody T., (2011). "Without Jobs as CEO, Who speaks for the Arts at Apple?”. Wired. Aug. 29, 2011.

Korshunova, S.A. (2018). Features of formation of scientific philosophical outlook in students of technical university under conditions of new model of education. Alma mater (Higher School Herald), vol. 2.

Korshunova S.A. (2020). Youth of today in the context of digital society development. 7th International conference on education and social sciences. Abstracts \& Proceedings.

Kuzminov Ya. (2018).Challenges and prospects for the development of universities in Russia. University management: practice and analysis, T. 22. vol. 4 (116).

Kuzminov Y., Frumin I. (2018). Twelve Solutions for a New Education: Report by the Center for Strategic Research and the Higher School of Economics (eds. Y. Kuzminov, I. Froumin), Moscow: HSE.

Matteson M.L., Anderson L. and Boyden C. (2016). Soft Skills: A Phase in Search of Meaning. Portal: Libraries and the Academy. vol. 16.

Mitchell G., Pritchett C., and Skinner L. (2013). "The Importance of the Integration of Soft Skills into the Curriculum as Identified by MBA Students". Academy of Business Research Journal, vol. 2.

Raitskaya, L., Tikhonova, E. (2018). Perceptions of soft skills by Russia's university lecturers and students in the context of the world experience. RUDN Journal of Psychology and Pedagogics, vol.15(3).

Raitskaya, L., Tikhonova, E. (2019). Skills and competencies in higher education and beyond. Journal of Language and Education, T. 5. vol. 4 (20).

"Russia 2025: resetting the talent balance". The Boston Consulting Group. (2017): https://www.bcg.com/Images/Russia-2025-report-RUS_tcm27-188275.pdf/, last accessed 2020/03/20.

Tchoshanov, M.A. (2018). Digital age didactics: from teaching to engineering of learning (Part 1). Informatics and education, vol. 9.

Vaindorf-Sysoeva, M. E., Subocheva M. L. (2018). "Digital education” as a system-developing category: approaches to the definition. Bulletin of the Moscow state regional University. Series: Pedagogy, vol. 3.

Zmyzgova T.P. (2016). Formation of basis professional competences of students of technological majors with regard to the use of methods of mathematical and computer modelling. IT and Education. vol. 5 (274). 